\title{
Case study concerning successful Romanian SMEs development by students education and entrepreneurial training
}

\author{
Irina Radulescu ${ }^{1}$ and Alexandru V Radulescu ${ }^{1}$ \\ ${ }^{1}$ University POLITEHNICA Bucharest, Romania \\ E-mail: irina.radulescu@upb.ro
}

\begin{abstract}
The European Commission has published in 2020 the SMEs Strategy for a Sustainable and Digital Europe that aims to increase the number of SMEs engaged in sustainable business practices, as well as the SMEs number that use digital technologies. Important opportunities for SMEs can be provided by digitization, to improve the production processes efficiency and the ability to innovate products and business models, by using advanced disruptive technologies. Good management is needed for a successful SME, education and entrepreneurship training have the role of consolidating business knowledge and skills. Educational activities and skills upgrading are essential for all SMEs managers and employees. Romania is on the last place in EU, regarding SMEs number and it ranks 11th place out of 28 , in terms of connectivity. Regarding the digital maturity of Romanian SMEs, the White Papers on Romanian SMEs presents their main working elements: computer, e-mail applications, internet, intranet, social networks, the company's own website, online sales / purchases transactions. The objectives of the Bachelor's degree specialization of Economic Engineering in Mechanical field and Industrial Entrepreneurship Master are students training and education, in order to be able to sustain digitization and sustainable technologies. The university curriculum and the educational disciplines offered by the Economic Engineering in Mechanical field specialization and Industrial Entrepreneurship Master is connected to the society requirements and must follow the economic trend, by educating, training and getting good specialists.
\end{abstract}

Keywords: SMEs development, education, entrepreneurship

\section{The international situation. European Union policy regarding SME strategy for sustainable and digital Europe}

The SMEs key role is to create added value for each economic sector and it is marked by the 25 million SMEs of Europe, which represent the "spinal column of the European Union economy", providing jobs for approximately 100 million people and contributing for more than half of Europe's GDP. They play a key role being deeply integrated into the Europe economic and social structure, by creating training opportunities in all regions and sectors and supporting the well-being of society, by providing two out of three jobs.

The European Commission has published the SMEs Strategy for a Sustainable and Digital Europe, which proposes actions based on the following pillars:

- Capacity consolidation and supporting the transition to sustainability and digitalisation;

- Reducing the regulatory task and improving market access;

- Improving access to finance. 
The strategy aims to increase the number of SMEs engaged in sustainable business practices, as well as the SMEs number that use digital technologies. The ultimate goal is to transform Europe to become "the most attractive place for small or medium-sized enterprise foundation, in order to make it grow and help it to expand on the market" [1].

"Competitive sustainability represents the Europe's guiding principle for the future. Achieving a flexible, resource-efficient and climate-neutral digital economy requires the full mobilization of SMEs. Considering an economic, ecological and social point of view, the transition toward a sustainable Europe follows the transition to digitalisation "[1].

According to statistics, in Europe there are many well-equipped, high-tech, innovative SMEs committed to respecting sustainability and circular economy values. Almost a quarter of European SMEs offers green products or services, but only $17 \%$ of SMEs business have successfully integrated digital technologies, compared to $54 \%$ of large enterprises.

Important opportunities for SMEs can be provided by digitization, to improve the production processes efficiency and the ability to innovate products and business models, by using advanced disruptive technologies: blockchain technology and artificial intelligence (AI), cloud technology and high performance computing (HPC), [1].

Good management is needed for a successful SME, education and entrepreneurship training have the role of consolidating business knowledge and skills. Educational activities and skills upgrading are essential for all SMEs managers and employees, with a particular focus on empowering women to set up SMEs and on improving the gender balance among business managers, [ 2].

Considering the digital Europe program, the Commission will develop intensive courses in the digital field to enable SME employees to acquire advanced skills in artificial intelligence (AI), cybersecurity or blockchain technology, based on the experience gained within the Coalition for Skills and Jobs in the digital sector platform. The Commission will launch a "digital volunteers" program to enable qualified young people and experienced older people to share their digital skills with traditional businesses. Same time, the Commission will support and interconnect SME intermediaries, such as clusters, to help SME staff to update their skills in sustainability field. The Commission will update the Europe Skills Agenda, including a Pact for Skills with a specific SMEs component, and it will propose a Council Recommendation to modernizing vocational education and training, [3].

"Erasmus for Young Entrepreneurs" initiative gives young people the chance to work together with an experienced entrepreneur from another European Union country, in order to help set up their own business or develop an existing one. The basic idea is that the young person, as an EU citizen, has the right to start a business in any country of the Union or to set up in another Member State a subsidiary of a company already established in the EU. The requirements differ from country to country, so it is important to know the procedures to be followed, [4].

\section{The national situation regarding Romanian entrepreneurship compared to European Union}

Regarding SMEs Romania's situation related to the country's population, this indicator increased after Start-Up Nation, the SMEs financing program introduced by the state ; however, Romania remained on the last place in the European Union.

In 2018 Romania had 29 micro and small and medium enterprises (SMEs) per 1,000 inhabitants, well below the European average, which was 58 SMEs per 1,000 inhabitants, remaining on the last place in EU. Only $10 \%$ of Romanian SMEs had innovation activity, being also on the last place in EU.

The 2019 European Report shows that a former communist country, the Czech Republic, has the most SMEs per 1,000 inhabitants (115), but developed EU countries, such as the United Kingdom and Germany, do not have many SMEs per thousand inhabitants. There are 7 EU countries with less than 50 SMEs per 1,000 inhabitants: Austria, Germany, Denmark, Finland, Croatia, Romania and the United Kingdom. Romania is on the last place in EU, regarding SMEs number, the next ranked being Germany (35 SMEs per 1000 inhabitants), Great Britain (38 SMEs per 1000 inhabitants). Analysing the development, average wages or GDP per capita, the Central and Eastern European region countries, which Romania is compared to, are better placed. 
In 2018 Romania had 485,757 SMEs in the non-financial sector, representing $99.7 \%$ of all country companies; $88.4 \%$ of them were micro-enterprises, $5.9 \%$ of them were small companies and $1.8 \%$ of them were medium-sized companies. In 2019 Romanian SMEs generated 52.7\% of total added value of the non-financial business sector. Also, SMEs had 65.8\% of the total employees in the Romanian nonfinancial business sector. The average productivity of Romanian SMEs was about 15,100 euros, being calculated as added value for each employee, which is significantly lower than the EU average (about 44,600 euros). Romanian SMEs employed an average of 5.5 people, exceeding the EU average of 3.9.

The European Commission Report shows the Romanian Government efforts to finance new companies establishment, as Start-Up Nation program, but also it suggested to take action to reduce bureaucracy to help entrepreneurs, [5].

An useful tool is the SME INVEST ROMANIA program, the government's response to the health and economic crisis, in the context of the COVID-19 pandemic. Its objective is to support the entrepreneurial environment, facilitating access to SMEs finance, to ensure the necessary liquidity to continue economic activity, by accessing one or more investments and working capital credits, guaranteed by FNGCIMM (National Credit Guarantee Fund for Small and Medium Enterprises), [6].

Before COVID crisis, 2019 showed a business environment problem identified by companies: staff hiring, training and maintaining. The President of the Romanian SMEs National Council shows that in 2019 the labor crisis has deepened, the survey of 788 SMEs informed that $57 \%$ of them noted that hiring, training and maintaining employment represents a difficulty; in 2018 the percentage was 46. The perception of bureaucracy as a problem remained at the same threshold, respectively $48 \%$. In 2018, inflation ranked fifth in the top of the SMEs problems, but in 2019 it rose to third place (47\%), after unfair competition.

Ovidiu Nicolescu, Honorary President of CNIPMMR (National Council of Romanian Small and Medium Private Enterprises) said that half of the Romanian SMEs have problems, although they provide half of the Romanian gross domestic product (GDP) and they largely contribute to exports. He stated that: "14.28\% have increased their activity in the last two years (that represents 1 of 7 SMEs) and a third part $(35.48 \%)$ operates at the same parameters. All of these shows that half of the SMEs give stability, but, at the same time, half of the SMEs have problems, $11 \%$ of SMEs are in bankruptcy situation and almost $40 \%$ have reduced their activities. "This is a very high percentage. This is the picture of the last two years that we have to keep in mind when we foreshadow measures."

According to Act Factsheet 2019 for Romania, the European Commission Small Business Report, SMEs represent $99.7 \%$ of companies in the economy and $66 \%$ of employees. It is essential to guide, support and coordinate these companies digitization. The national programs as Start-Up Nation, POR Axis 2 regional programs had a digitization component, being a founding source for SME digitization projects.

The 2020 Economy and Digital Society Index Report (DESI) shows that Romania ranks 11th place out of 28, in terms of connectivity, it emphasizes the great need for digitalization of Romanian SMEs.

Regarding the digital maturity of Romanian SMEs, the White Papers on Romanian SMEs shows that the main elements used by Romanian SMEs are the computer, e-mail applications, internet, intranet, social networks, the company's own website, online sales / purchases transactions.

By developing the "SMEs capacity strengthening to adapt to the 4.0 Industrial Revolution" project, the Bucharest-Ilfov Regional Intermediate Body launched "The Report on public policies on SMEs digitization, that have been identified to be improved and good local practice examples." This report was built following main steps [7]:

- Global, regional and national context on the SMEs digitalisation,

- The need to develop digital skills,

- Digital maturity of Romanian SMEs,

- Public policies analysis on SMEs digitizing,

- Good practices on public policies that support the SMEs digitization,

- Other public policies for SMEs digitization, to be developed or improved. 


\section{Adapting the education system to the society requirements by students' activity analysis}

This chapter presents students activities and makes connection between education system and the society requirements, by analyzing Bachelor's Degree projects of the Economic Engineering in the Mechanical Field Specialization - and Master's Degree projects at the Industrial Entrepreneurship.

Digital education is one of the 4 strategic axes of the current government program, together with digital administration, digital economy and digital society; the ultimate goal is to achieve an "accelerated digitization" process, to contribute to the economy, public administration and society profound transformations, to increase public sector performance and efficiency.

To have competitive SMEs on the market, rapid digitization is necessary and the digital education is a must, by including a cross-cutting level of technology in all educational processes, but especially by implementing acquisition policies / increasing / improvement of digital competences, from the school level to the entire Romanian society level, [8].

An education and training system adapted to the technological evolution adapted is required to prepare and improve human resources, being essential for the society development.

The digital technology use can develop all levels skills by a lifelong education, also being developed a more attractive school to students, more adapted to their needs and lifestyle. Romanian digital transformation in education is determined by advances in connectivity, by the widespread use of devices and digital applications, according to individual flexibility and the digital skills demand.

The "Covid-19" crisis has emphasized these transformations demand, considering the online environment interaction, by outlining a teaching and learning system connected to digital technology. It also highlighted "the role of digital education as a key objective for high quality, accessible and inclusive teaching-learning-assessment, also the requirement for a strategic approach regarding the digital skills acquisition throughout life, for all actors".

Currently, the integrated approach of all public services digitalization aspects, including education field, is ensured by the Romania 2020 National Strategy for the Digital Agenda provisions.

Romania Internet connectivity has a wide coverage, but still "steps are needed to ensure all resources and an integrated framework for access to quality education in the digital age." Future actions aim a closer cooperation with all stakeholders to generate a Modern, Accessible School, based on Digital Resources and Technologies - "SMART-Edu" ; They start from the following priorities:

1. Accessibility - providing digital infrastructure and emerging technologies for access to inclusive and quality education;

2. Connectivity - digital skills developing for a digital transition to a competitive society, focused on sustainable development, social equity and resilience; digital literacy and misinformation fighting; use of open educational resources;

3. Community - stakeholder consultation and involvement;

4. Digital educational ecosystem - creating a high performance digital educational environment respecting digital ethics, personal data protection, cyber security, data analysis, etc;

5. Innovation - use of all digital resources and technologies, creativity and entrepreneurship stimulation;

6. Sustainability - medium and long-term predictability provision by inter-sectoral cooperation, for quality education and a green and digital economy [9].

The directions of action have as main subjects - children and young people - and they are based on the following principles respecting: equal access, equity, inclusion, learning personalization and digital skills acquisition, sustainable development, quality, resilience, green economy, [9].

The 4 years Bachelor's degree education in Economic Engineering in the Mechanical Field offer for students to achieve digital skills, being able to develop projects ; their data are collected, analyzed and statistically processed by using specialized software, in respect of digital ethics and personal data protection (Fig. 1). 
Digital skills projects - Bachelor's degree education in Economic Engineering in the Mechanical Field

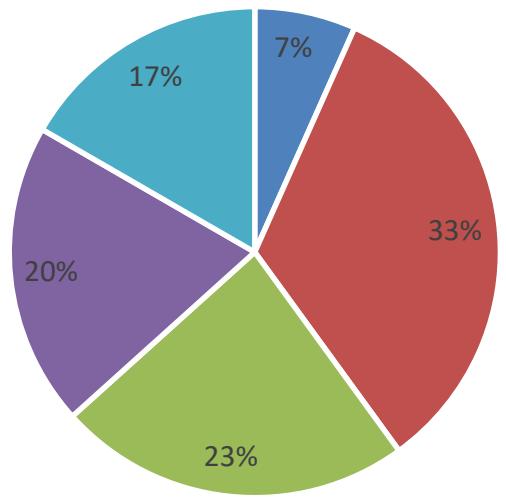

\author{
- Projects / technical-economic analyzes / \\ statistical analyzes \\ - Projects / technical-economic projects \\ and ARENA simulation software \\ analyzes \\ - Projects / technical-economic analyzes/ \\ 3D SOLID WORKS projects \\ - Projects / technical-economic analyzes/ \\ 3D CATIA projects \\ - Projects / technical-economic analyzes/ \\ 3D AutoDesk Inventor projects
}

Figure 1. Digital skills projects - Bachelor's degree education in Economic Engineering in the Mechanical Field

The Bachelor studies projects have the subjects in technical-economic analysis domain, in different fields of interest, such as: environmental protection, theoretical and experimental studies to improve computational performance, projects and technical-economic analysis on mechanical devices and equipment and technological processes. Some examples of these themes are: Plastic coaxial reducer for terrestrial drones, Thermal-economic analysis of passive house systems, Technical-economic analysis of electric and hybrid vehicles braking systems, Technical-economic analysis of equipment used in commercial mountaineering, Theoretical and experimental study on improving computing performance of a personal computer, Analysis and optimization in an IT Support department of a telecommunications company, by using the ARENA software, Resources management in the manufacturing process of medical masks, (Fig. 2).

Theme Projects- Bachelor's degree education in Economic Engineering in the Mechanical Field

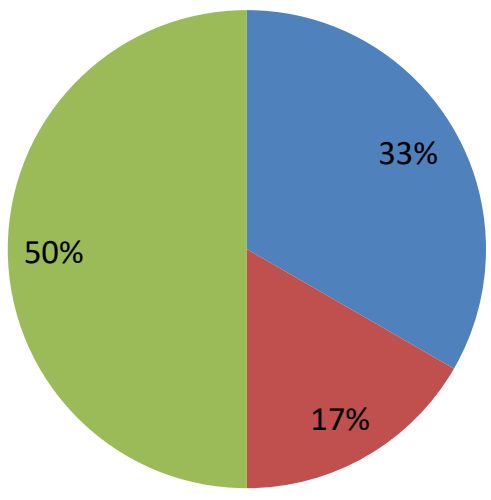

- Projects / technical-economic analysis in the field of environmental protection

- Projects / Theoretical and experimental studies to improve computational performance

- Projects / technical-economic analysis of mechanical devices and equipment

Figure 2. Bachelor's degree projects -Economic Engineering in the Mechanical Field 
Industrial Entrepreneurship Master's degree gives a students offer to continue to develop digital skills and analytical thinking, by presenting projects based on eco-design, green economy and sustainable development and using statistical analysis, developing questionnaires and using mathematical modeling and simulation. The figure below shows the Industrial Entrepreneurship Master favorite fields for the range of projects focused on green economy: photovoltaic panels, ecological materials, electrical and electronic waste recovery, ecological agriculture, plastic recycling (Fig. 3).

\section{Green economy projects - Industrial Entrepreneurship Master degree}

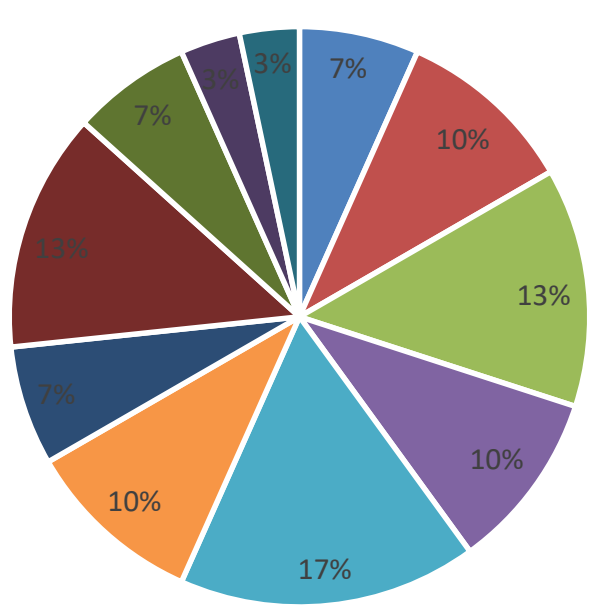

- Photovoltaic panel projects

- Ecological materials projects

- Electrical and electronic waste Recovery Projects

- Organic farming projects (smart agriculture)

- Plastic, rubber recycling projects

- Projects of companies that protect the environment (electricity)

- Ecological Cities Projects

- Recyclable packaging projects

- Wind energy projects

- Housing Eco-design Projects

- Biodegradable textile projects

Figure 3. Green economy projects for Industrial Entrepreneurship Master

Industrial Entrepreneurship master's students complete their dissertation most often with business plans in different fields: industrial area, industrial processes quality management, agriculture, tourism, insurance companies, services and consumer goods, telecommunications companies, medical optics, construction, culture and sport, (Fig. 4).

Dissertation projects of master's students in Industrial Entrepreneurship

- Business plans for industrial companies / quality management in industrial processes

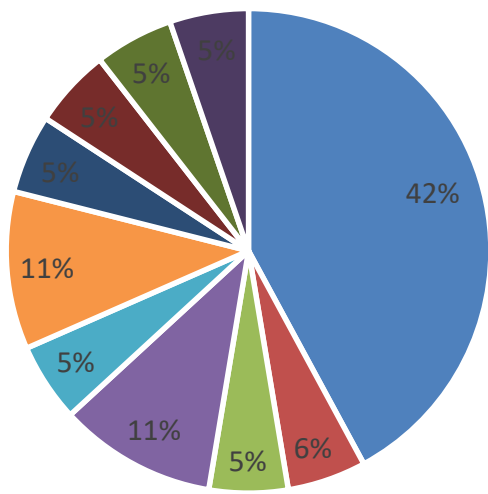

- Business plans for the development of

companies in the sports field

- Business plans for agricultural companies

- Business plans for tourism companies

- Business plans for tourism companies

- Business plans for companies in the field of services and consumer goods

- Business plans for companies in the field of telecommunications

- Business plans for companies in the field of culture

- Business plans for companies in the field of medical optics

- Business plans for construction companies

Figure 4. Dissertation projects themes in Industrial Entrepreneurship Master 


\section{Conclusions}

Opportunities to improve the Romanian SMEs production processes efficiency and their innovation capacity are based on managers strategic thinking education, on their good digitalization training towards eco-sustainable business models.

A successful SME requires good management, so the emphasis is on entrepreneurship education that consolidates and improves business knowledge and skills. The education system is adapted to the requirements of today's society, being achieved by personalization of learning, acquiring and developing of digital skills, education on sustainable development, quality, promoting the green economy.

Main elements SMEs employees are using today are: computer, mail applications, internet, intranet, social networks, company website, online sales / purchases transactions, that are based on very good connectivity and high internet speed. Experience and digital maturity of users only need the entrepreneurial environment support and a well-trained workforce provision in companies.

The objectives of the Bachelor's degree specialization of Economic Engineering in Mechanical field and Industrial Entrepreneurship Master are represented by the students training and education according to previous directions, their researches during the 4 study years and the bachelor's and dissertation projects being a relevant example.

During the 4 years of the bachelor's degree the students specialized in Economic Engineering in Mechanical field focuse on technic researches related to practical and economic aspects.

Industrial Entrepreneurship Master offers the opportunity to do an in-depth analysis of their researches related to business plan developing.

The university curriculum and the educational disciplines offered by the Economic Engineering in Mechanical field specialization and Industrial Entrepreneurship Master is connected to the society requirements and must follow the economic trend, by educating, training and getting good specialists.

\section{References}

[1] European Commission Brussels, 10.3.2020 COM (2020) 103 final, Communication of the Commission to the European Parliament, The Council, The European Economic and Social Committee and The Regions Committee. An SME strategy for a sustainable and digital Europe.

[2] COM (2020) 152 final, Gender Equality Strategy 2020-2025, 4.3.2020.

[3] European Commission Brussels, The 2018 report of the Working Group on Digital Innovation Centers, https://ec.europa.eu/futurium/en/system/files/ged/dihs_access_to_finance_report_final.pdf

[4] https://europa.eu/youth/go-abroad/working/erasmus-young-entrepreneurs_ro

[5] https://www.startupcafe.ro/finantari/startup-nation-imm-romania-raport-2019.htm

[6] https://www.fngcimm.ro/imm-invest

[7] https://www.oirbi.ro/category/strengthening-sme-capacity-to-engage-in-industry-4-0/

[8] https://insse.ro/cms/ro/

[9] https://www.smart.edu.ro/ 